\title{
Diesel engine diagnostic training program
}

\author{
Alexander Ivanov ${ }^{1}$, Vladimir Konovalov ${ }^{2, *}$, Vladimir Lyandenbursky ${ }^{3}$, Yuri Rodionov ${ }^{3}$ and \\ Yuri Zakharov ${ }^{3}$ \\ ${ }^{1}$ Penza State Agrarian University, 30, Botanical Street, 440014, Penza, Russia \\ ${ }^{2}$ Penza State Technological University, 1A/11, Baydukova Travel / Gagarina Street, 440039, Penza, \\ Russia \\ ${ }^{3}$ Penza State University of Architecture and Construction, 28, Titov Street, 440028, Penza, Russia
}

\begin{abstract}
To optimize the learning process of working methods and the study of diagnostic equipment, it is advisable to use virtual simulators that simulate the process. The created virtual model vKAD-400 reproduces almost all the actions performed by the master diagnostician in determining the technical condition of a diesel engine. In the process of modeling using the editor, the algorithm of the "Diesel-Diagnostics" program was developed using the method of digitizing existing waveforms. Using the computer program "Diesel-Diagnostics" will reduce the cost of training students and technical personnel.
\end{abstract}

\section{Introduction}

Reliable operation of technical systems of vehicles is determined by the operability of its individual systems [1], nodes [2, 3] and structural elements [4, 5]. Technical diagnostics of both vehicle components and its design as a whole is aimed at determining the technical condition [6-8], searching and localizing the place of failure or malfunction [9, 10], predicting the residual life or the probability of failure-free operation [11-13].

For timely repair and correct troubleshooting of machine malfunctions, experienced and competent specialists should service the equipment. Without special training, they are not prepared. Students get the basic skills of working with technological equipment during laboratory work on computer models or working equipment. During training, difficulties arise, determined by the features of equipment for diagnosing automobiles.

The equipment used is very expensive; the number of jobs is limited. This leads to the fact that not all students succeed in performing specific actions, according to the technology for diagnosing a car on equipment, by far. Basically, they gain knowledge by passively observing the use of equipment by a training master or teacher. The use of the fast method of conducting classes is limited by the insufficient number of training masters, especially with a small number of students on the stream.

In this situation, the most effective solution is to simulate the processes of maintenance and diagnostics on a computer. This will allow each student to complete the entire laboratory work algorithm, individually working with a computer model of a particular equipment.

* Corresponding author: konovalov-penza@rambler.ru 
A virtual model was adopted as an object for the development of a computer model, which reproduces all the necessary actions performed by a diagnostician in assessing the technical condition of a diesel engine.

The use of expensive equipment in the educational process is associated with significant operating costs. Therefore, for the purpose of teaching methods of working with such tools, it is advisable to use virtual simulators that simulate the diagnostic process.

\section{Research methods}

Modeling of the technical condition is carried out by setting parameters characterizing the performance of engine elements, certain values using a special editor. Training in the proposed program occurs according to the following algorithm (Figure 1):

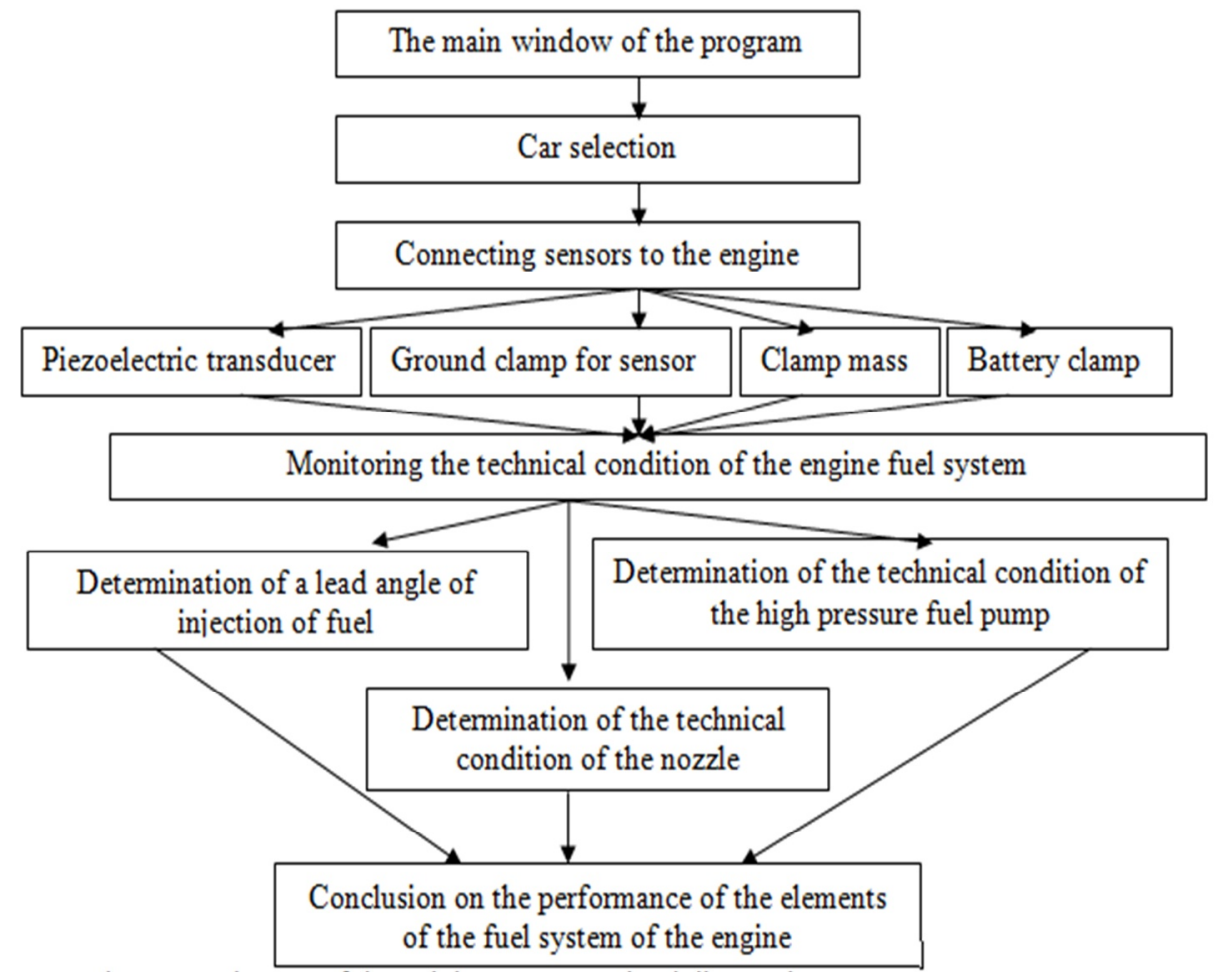

Fig. 1. Diagram of the training program Diesel diagnostics.

The Diesel Diagnostics program is designed to familiarize students with the process of diagnosing a diesel engine fuel system.

\section{Research result}

After starting the program, the main window (Figure 2) appears on which the name of the program and the controls are shown: a button to call up the program settings menu and buttons to select the diagnosed car with a diesel engine.

Choosing a car, the student receives a task to connect the primary transducers, shown in Figure 3 on top of the engine, to the control points located on the engine and the battery. 
The status bar at the bottom of the figure provides information on the current action related to connecting the primary converter.

After completing the connection of the auto-diagnostic complex, the student goes to the "Advance" mode window (Figure 4), from which one can estimate the advance angle of the fuel supply and assess the presence of a malfunction of the fuel system elements.

At the bottom of the window are the window call buttons with the norms of the advance angle of fuel supply (F1), button "F3 Stroboscope", button "F4 Oscillogram" and button "Salon", which provide a call to the desired window in the process of simulating the diagnosis of a diesel engine.

To ensure the diagnostic mode, it is necessary to set the required number of revolutions of the crankshaft of the engine, after having previously entered the vehicle interior (Figure 5).

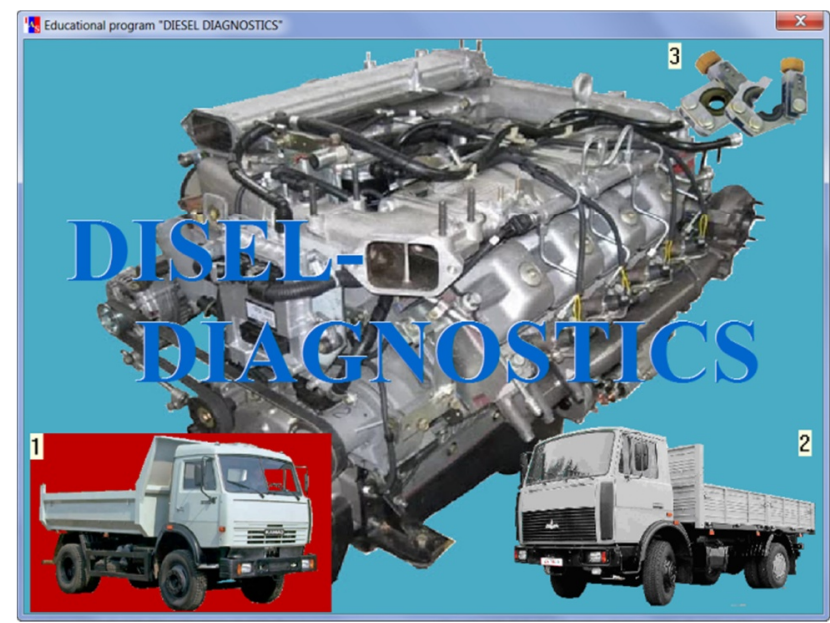

Fig. 2. The main program window.

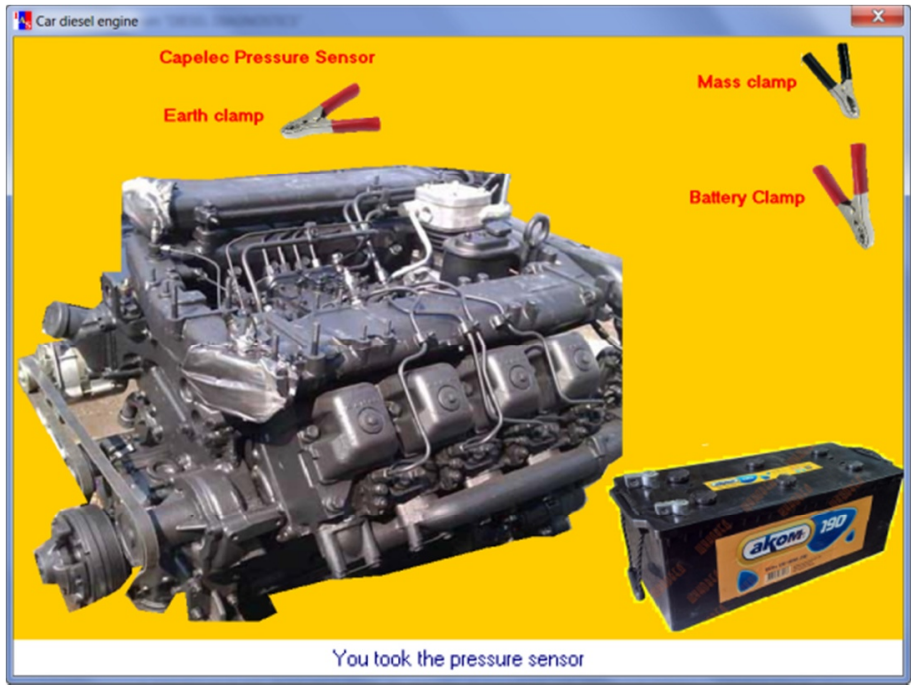

Fig. 3. Window with connection points of primary converters to the engine.

In the cabin, use the "mouse" manipulator to shift the simulator (slider) of the ignition key to the far right position, the field of which the engine will start and the number of revolutions of HF will be indicated in the window, both in numerical and in analog form. 


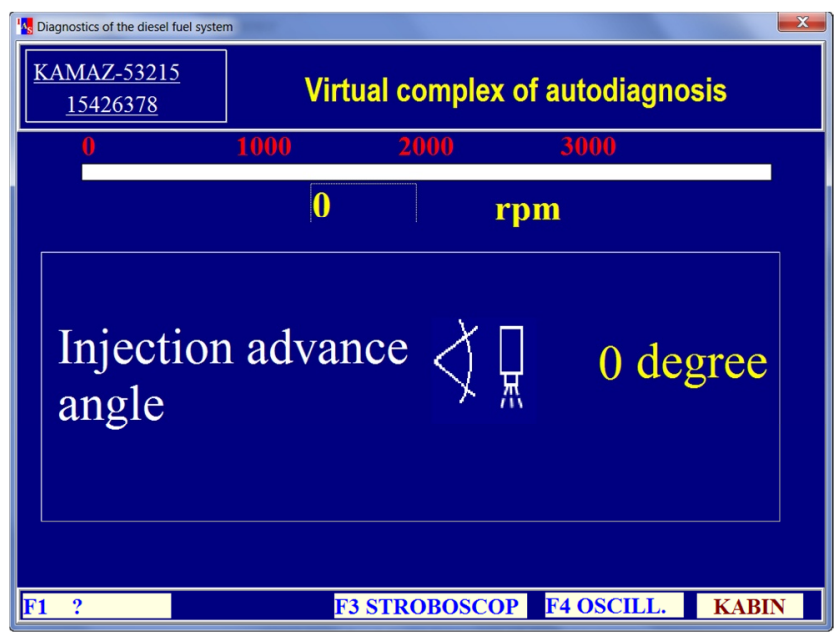

Fig. 4. Window for monitoring the technical condition of the fuel system of a car (Advance mode).

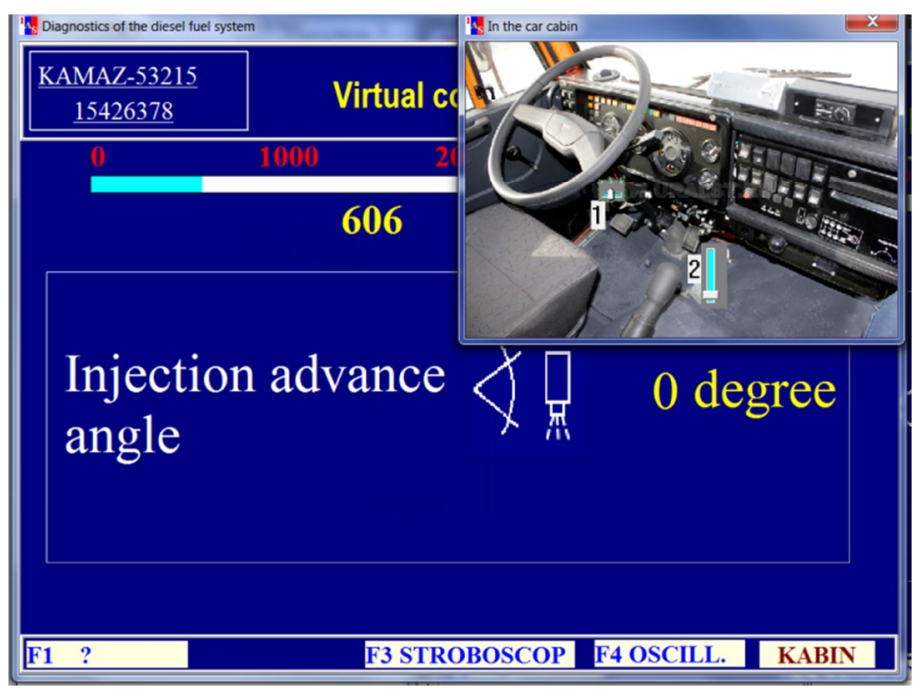

Fig. 5. Window for monitoring the technical condition of the fuel system of a car (Vehicle interior).

The number of revolutions can be changed using the control element (slider) located in the area of the fuel pump rail control pedal.

The next action is to call the window to perform actions with a strobe (Figure 6). On the right is a gif-picture of the front of the diesel engine with rotating pulleys and a belt. On the left is a strobe of the auto-diagnostic complex with controls: a button for switching on a flash lamp and buttons for changing the moment of flash of the lamp.

A mouse click on the power button simulates the inclusion of a stroboscopic lamp, as a result of which it starts to blink, the front surface of the engine lights up and a stroboscopic effect occurs - it seems to the user that the illuminated rotating parts stop rotating. At the same time, he sees a mark on the belt drive pulley (yellow dot) which is located in the mark area on the cylinder block (yellow triangle).

Next, by clicking on the button for changing the moment of flash of the lamp, position the mark on the pulley opposite the mark on the block and end this process by pressing the strobe button. As a result, the window with the strobe closes and the user sees the measured angle of advance of the fuel supply (Figure 4). By repeating these steps at different speeds 
of the crankshaft rotation, one can evaluate both the initial feed advance angle and the operation of the automatic fuel feed advance coupling.

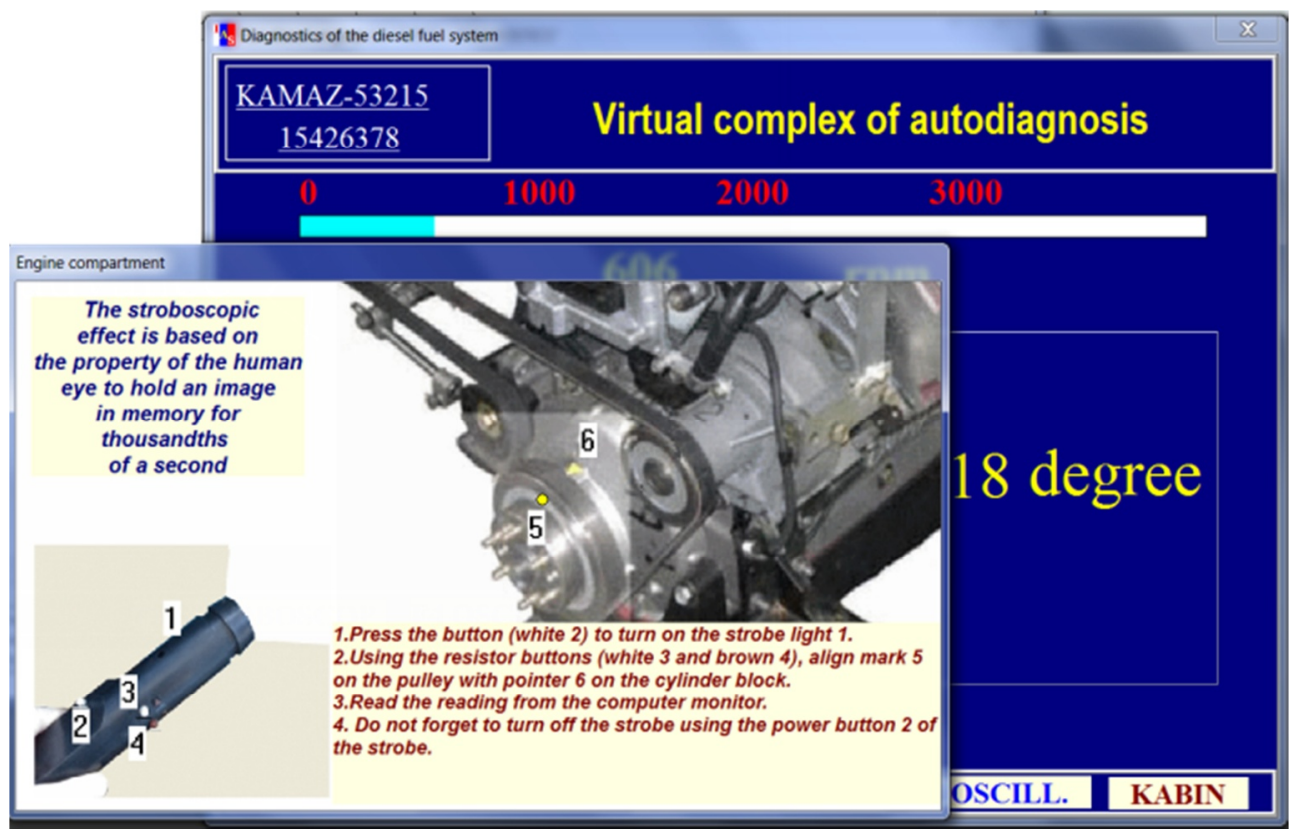

Fig. 6. Modeling the operation of the strobe.

The performance of the instruments of the high-pressure circuit of the fuel system can be assessed using the waveforms obtained using the Capelec overhead piezoelectric pressure sensor, which is mounted on the high-pressure pipeline (Figure 4).

Pressing the F4 button brings up a window with a pressure waveform (Figure 6).

The student should, by the appearance of the current waveform, identify a possible malfunction of an element of the fuel system of the engine.

The change in pressure $\mathrm{P}$ as a function of time $\mathrm{t}$ is analyzed as follows. At point 1 , an increase in pressure begins as a result of the movement of the plunger of the pump, at point 2 , the discharge valve is activated, and at a low speed of movement of the plunger, the pressure increase slows down for a while. At point 3, the nozzle needle rises. In this case, the pressure drops, because the released volume does not have time to fill with fuel, and then rises again to a certain value.

Point 4 at a high engine speed can indicate the maximum pressure of the injection process. However, for a normal process in idle mode, this pressure is usually fixed at the characteristic peak of point 3. At point 5, the nozzle needle "fits" and injection stops, after which the "fit" of the plunger discharge valve into the seat. Residual pressure pulses (6) result from insufficient tightness of the discharge valve. The value of the signal S1 determines the tightening of the nozzle spring and the static pressure of the start of injection. The differential pressure $\Delta \mathrm{P}$ characterizes the mobility of the nozzle needle. By integrating during the injection period tvpr it is possible to estimate the cyclic fuel supply. Injection delay time S2 characterizes the clearance in the plunger pair, causing fuel leakage between the sleeve and the plunger.

As you can see, the influence of various malfunctions of the diesel fuel system on the type of oscillograms of high pressure pulsations is very diverse and it is difficult for a novice diagnostician to determine the cause of a failure by the appearance of an oscillogram. 
Preliminary preparation is necessary, which should take place in conditions close to production, i.e. a possible change in pressure in the fuel system corresponding to a given malfunction should be reproduced on the computer screen, and the diagnostician must correctly identify it.

To facilitate the troubleshooting process, along with the current waveform 1 (Figure 7), a control waveform 3 corresponding to the operational state of the fuel system is also provided in the window. In addition, by rotating the mouse wheel, it is possible to sort through possible waveforms 2 for a given diagnostic mode and compare them with the current waveform. Such a visual comparison should help students remember the characteristic features of the oscillograms for various malfunctions.

For this purpose, a module has been introduced that reproduces pressure oscillograms in the high pressure circuit of the fuel system for various malfunctions of the power system elements.

Since it is not possible to describe the oscillograms of pressure changes by analytical dependences, when creating the waveform database, the method of digitizing existing waveforms was used, which were previously prepared in a scale convenient for subsequent use along the abscissa axis taking into account the duration of the fuel injection process (Tp) and ordinates (Figure 8) .

When digitizing the waveform for each point, the coordinates (Xi, Yi) were determined. The totality of these data pairs was transformed into a Paradox database management system file.

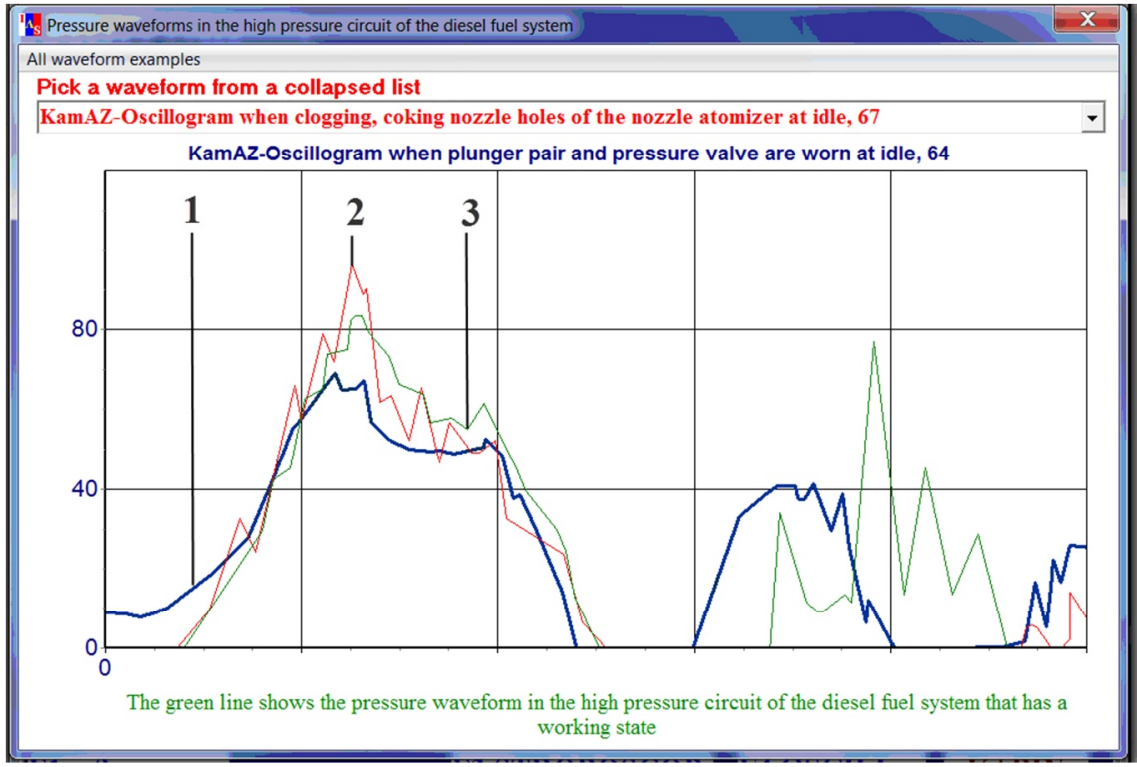

Fig. 7. Window with a pressure waveform in the high pressure circuit of the fuel system: 1 - current, recorded by the sensor, waveform, 2 - waveform selected from a collapsed list of possible waveforms, 3 - control oscilloscope corresponding to the operational state of the fuel system. 


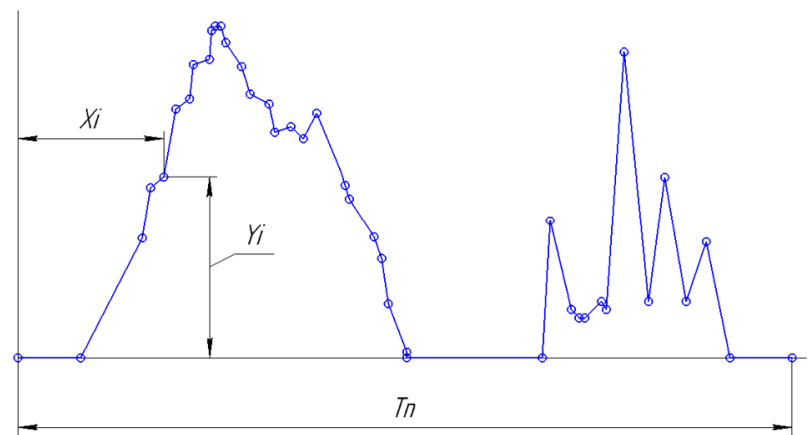

Fig. 8. Digitization of the fuel pressure graph.

Going through the malfunctions existing in the database, the student can find visually matching waveforms of blue color 1 (Figure 6) (waveform of the diagnosed engine) and red color 2 (waveform from the database corresponding to the known fault), i.e. determine the malfunction of the diesel fuel system.

\section{The conclusion}

Thus, the learner has at his disposal a whole arsenal of capabilities of modern selfdiagnostic complexes. He can not only reproduce the actions, but also get specific values and dependencies of the change in the diagnostic parameters, which will make it possible to draw an appropriate conclusion about the operability of the engine fuel system.

Modeling of computer diagnostic equipment will significantly accelerate the learning process. After this kind of training, the student will be able to more consciously perform the diagnosis of the diesel engine, with the least expenditure of time and money.

\section{References}

1. A.V. Gritsenko, Z.V. Almetova, V.V. Rudnev, Lecture Notes in Mechanical Engineering, 829-838 (2020) DOI https://doi.org/10.1007/978-3-030-22041-9_122

2. T. Osipowicz, W. Gołębiewski, Journal of KONES Powertrain and Transport 23, 3 (2016) DOI: 10.5604/12314005.1216597

3. A. Karaduman, H. Lekesiz, A. Yildiz, SAE Technical Paper 01, 1424 (2019) https://doi.org/10.4271/2019-01-1424

4. F. Kh. Khaliullin, J.K. Aladashvili, A.A. Nurmiev, G.V. Pikmullin, S.A. Sinitsky, IOP Conference Series: Materials Science and Engineering 635(1), 012017 (2019) doi:10.1088/1757-899X/635/1/012017

5. I. Rogovskii, L. Titova, A. Novitskii, V. Rebenko, Engineering for Rural Development 18, 291-298 (2019) DOI: 10.22616/ERDev2019.18.N451

6. F.Kh. Khaliullin, A.V. Matyashin, R.R. Akhmetzyanov, V.M. Medvedev, M.A. Lushnov, IOP Conference Series: Materials Science and Engineering 635(1), 012016 (2019) DOI: 10.1088/1757-899X/635/1/012016

7. N.S. Kochev, B.P. Zhilkin, L.V. Plotnikov, E3S Web of Conferences 124, 01014 (2019) https://doi.org/10.1051/e3sconf/201912401014

8. R.F. Salikhov, Y.P. Makushev, G.N. Musagitova, L.U. Volkova, R.S. Suleymanov, AIP Conference Proceedings 2141, 050009 (2019) https://doi.org/10.1063/1.5122152 
9. A.V. Gritsenko, V.D. Shepelev, A.G. Karpenko, Lecture Notes in Mechanical Engineering, 1175-1182 (2020) DOI https://doi.org/10.1007/978-3-030-22041-9_122

10. A.I. Karlina, V.E. Gozbenko, S.K. Kargapol'tsev, Y.I. Karlina, Journal of Physics: Conference Series 1384(1), 012019 (2019) DOI: 10.1088/1742-6596/1384/1/012019

11. A. Vozmilov, D. Vlasov, K. Glemba, Lecture Notes in Mechanical Engineering, 679686 (2020) DOI: 10.1007/978-3-030-22063-1_72

12. J. Monieta, Applied Sciences (Switzerland) 9(8), 1540 (2019) DOI: 10.3390/app9081540

13. A.V. Gritsenko, I.V. Makarova, G.N. Salimonenko, Lecture Notes in Mechanical Engineering, 783-793 (2020) DOI https://doi.org/10.1007/978-3-030-22041-9_122 